\title{
Presentación
}

\section{EST y la importancia de las ciudades ${ }^{1}$}

La revista Economia, Sociedad y Territorio (EST) se enfoca directamente en las ciudades, razones diversas justifican el interés por esta temática, entre ellas debemos considerar que, desde 2008, el mundo se enfrenta a un fenómeno nuevo: por primera vez en la historia de la humanidad, más de la mitad de la población vive en ciudades. Más de $90 \%$ del crecimiento urbano se localiza en países en desarrollo, lo que representa alrededor de 70 millones de nuevos habitantes en ciudades cada año; para 2030, los asentamientos urbanos del mundo en desarrollo representarán $80 \%$ de la población urbana mundial. En los próximos 20 años, el Homo sapiens ("el hombre inteligente") se convertirá en el Homo sapiens urbanus en prácticamente todas las regiones del planeta.

Sin embargo, el desarrollo y el crecimiento económico no se generan en todas partes ni al mismo tiempo. Los mercados favorecen algunos sitios y dejan de lado otros, además, desconcentrar la producción en el territorio no necesariamente contribuye a la prosperidad de todos; la evidencia muestra que las naciones con desempeño económico satisfactorio impulsan la concentración de la producción y, simultáneamente, diseñan políticas que tienden a reducir las desigualdades en las condiciones de vida de la población.

Dado que la producción se concentra en las grandes ciudades, se reconoce que las áreas urbanas de gran escala son los motores del crecimiento económico y el desarrollo humano en el siglo XXI. No obstante, las concentraciones urbanas generan una serie de externalidades negativas que afectan a la población. Por ejemplo; inseguridad y altos costos de aglomeración, por mencionar sólo algunas. Entonces, ¿por qué la población y las empresas siguen concentrándose en las ciudades? La razón es

${ }^{1}$ Tomado de Carlos Garrocho (2013), Dinámica de las ciudades de México en el siglo XXI, ONU Fondo de Población-Conapo-El Colegio Mexiquense, México. 
sencilla: los beneficios de vivir y trabajar en las grandes ciudades son mayores a los costos que eso implica. Adicionalmente, los costos de oportunidad de quedarse en asentamientos rurales rezagados, a veces incluso opresivos, especialmente para las mujeres, son demasiado altos, por lo que las migraciones a las ciudades no se detienen.

Se puede afirmar que la mayoría de los problemas asociados a la urbanización acelerada no se derivan del crecimiento en sí, sino de la incapacidad de las instituciones locales, regionales y nacionales para enfrentar los retos del rápido crecimiento de las ciudades. En otras palabras: no hay un vínculo automático entre crecimiento urbano y problemas en la ciudad. Existe evidencia abundante de que las grandes ciudades generan espacios productivos más eficientes, apoyados en densidades más altas (para favorecer las interrelaciones entre firmas y personas), menores distancias (que se reducen conforme los trabajadores y las empresas incrementan su densidad) y menos barreras económicas. La economía global del siglo XXI depende en gran parte de las economías de escala, la especialización, los flujos de información y la generación y adopción de innovaciones para incrementar su competitividad.

El crecimiento económico es, por naturaleza, desigual en el territorio. Intentar homogeneizarlo y pulverizar espacialmente la actividad económica significa, literalmente, desalentarla; pero el desarrollo, aunque concentrado, puede y debe ser incluyente. La clave está en integrar económicamente a los grupos de población que viven en la trampa de la localización periférica, que significa que donde viven no hay trabajo, y donde hay trabajo no pueden vivir.

Emprender la integración económica implica conectar mejor las zonas rurales con las ciudades, y las periferias urbanas pobres con las partes más avanzadas de la ciudad; es decir, acercar las oportunidades de desarrollo a toda la población. En esto desempeñan un papel central la accesibilidad al empleo y los servicios básicos (i.e., educación, salud, abasto, seguridad, justicia) lo cual se logra con mejor infraestructura de caminos, vialidades y transportes y el aumento de la conectividad a partir del incremento de la disponibilidad de teléfono celular e internet. La accesibilidad y la conectividad tienen una importancia crucial porque las zonas rezagadas usualmente tienen una característica común: están funcional y económicamente alejadas de los lugares de vanguardia. Este aislamiento se debe combatir por todos los medios posibles.

La localización es una de las variables más importantes para explicar el bienestar de las personas. En el futuro próximo, un individuo nacido en Estados Unidos ganará cien veces más que uno originario de Zambia, y vivirá tres decenios más. Las ventajas o desventajas de la localización del territorio donde se vive y trabaja son muy importantes, especialmente en 
el mundo en desarrollo. El mejor predictor del ingreso es dónde se trabaja, y en este tema las ciudades son localizaciones estratégicas para acceder a las oportunidades de desarrollo, porque la producción y las oportunidades se concentran, a diferentes ritmos, de manera creciente en el territorio. Es decir, en las ciudades.

Esto no debe resultar sorpresivo, pues la producción en las economías desarrolladas del mundo contemporáneo se ha concentrado cada vez más hasta lograr un nivel de ingresos aceptable. Por esto, la idea de que las ciudades de los países en desarrollo son demasiado grandes y que se debería desacelerar la urbanización no tiene respaldo empírico. La concentración inclusiva parece ser la estrategia más eficaz si se quiere lograr que las ciudades efectivamente sean motores del crecimiento económico y el progreso social.

La aglomeración, las migraciones y la especialización están transformando la geografía económica de los países y las regiones más dinámicas del mundo. Las grandes ciudades, la movilidad, la conectividad de la población y el comercio eficiente han sido catalizadores del progreso desde hace más de dos siglos y siguen impulsando los lugares más dinámicos del planeta. En algún momento, la reducción sistemática de los costos de transporte y las comunicaciones hicieron pensar que la producción económica se distribuiría de forma ubicua en el territorio y tendería a la dispersión. Sin embargo, ocurrió lo contrario: la caída de los costos del transporte ha coincidido con una mayor concentración espacial de las actividades económicas. Existen diversas explicaciones para este fenómeno, pero las más reconocidas son las que apuntan a la creciente importancia de las economías de escala y aglomeración en la producción y el transporte, lo que impulsa la especialización, la productividad y la competitividad, y el hecho de que existe una gran masa de información clave de naturaleza tácita no codificada que sólo puede transmitirse de manera directa "cara a cara".

Sin embargo, por increíble que parezca, la distancia física también afecta la velocidad de transmisión de las Tecnologías de la Información y las Comunicaciones (TIC), fundamentales en la nueva economía, y en actividades tan importantes como las operaciones financieras en la Bolsa. "En un tercio de segundo (lo que dura un parpadeo) en los mercados financieros hay margen para realizar hasta 40,000 operaciones, la competencia por ver quién es más rápido lleva a los inversores a pelear el último picosegundo. Y una forma de lograrlo es limitar la distancia física. A menor distancia entre el cable de la máquina y la plataforma de negociación, más veloz será la operación. Cada 100 millas (160 kilómetros) de distancia podrían añadir un milisegundo al tiempo estimado para la ejecución de las órdenes de compra-venta. Todo un mundo de diferencia. Para solucio- 
narlo, las firmas han empezado a ubicar sus máquinas tan cerca como físicamente es posible del servidor del mercado. Las Bolsas les cobran una comisión por hacerles un hueco en sus instalaciones. Este servicio es conocido como colocation, y todos contentos" (Fernández, 2011). ${ }^{2}$

Es un hecho que ningún país ha conseguido niveles de ingreso satisfactorios sin industrialización y sin ciudades. Actualmente, la multiplicación de las ciudades en los países en desarrollo parece caótica, pero es necesaria; tiene antecedentes históricos en los países desarrollados y ofrece alternativas para reducir la pobreza. No hay alternativa: la concentración, la densidad y la reducción de los costos de transporte y comunicaciones requieren áreas urbanas de gran escala, pero eficientes, equilibradas, y que favorezcan la equidad y la cohesión social. Sin duda, las ciudades son clave para transitar de una economía agraria tradicional a una industrial y postindustrial altamente competitiva. Los gobiernos pueden facilitar este trayecto ampliando su perspectiva: impulsando las transformaciones socioespaciales necesarias para el desarrollo y no sólo los cambios sectoriales.

Mucho se conoce de las transformaciones sectoriales necesarias para el crecimiento económico. Sin embargo, se ha puesto menos atención a las transformaciones socioespaciales que también deben realizarse para que los países y sus regiones puedan desarrollarse. El aumento de la concentración (i.e. densidad, reducción de la distancia y los costos de transporte, incrementos de accesibilidad y conectividad) seguirá siendo clave para el avance económico y social de los países y sus regiones en el futuro próximo.

Conviene alentar la concentración espacial, aunque ya se sepa que esto genera en el corto plazo un crecimiento desbalanceado en el territorio. El desafío, entonces, es alinear las políticas de concentración con políticas de integración económica y social, y aprovechar las oportunidades que brindan las aglomeraciones urbanas. Las transformaciones socioespaciales bien conducidas generan, más pronto que tarde, un desarrollo económico incluyente.

Es claro que lo que pase en las ciudades de los países en desarrollo delineará el futuro del planeta en términos de crecimiento económico, reducción de la pobreza, estabilización demográfica, sostenibilidad ambiental y ejercicio de los derechos humanos. Quizá por esto, nunca antes las ciudades habían despertado tanto interés de los gobiernos, los organismos internacionales, los centros académicos y los sectores privado y social. Las ciudades exitosas progresan, mejoran sus finanzas, generan

\footnotetext{
${ }^{2}$ Fernández, David (2011), "En manos de la máquina”, El País, 4 de diciembre del 2011, ediciones el País, http://elpais.com/diario/2011/12/04/negocio/1323008065_850215.html, 22 de noviembre de 2016.
} 
oportunidades de desarrollo para todos, abren ventanas de negocios y se ocupan de sus habitantes más vulnerables.

Indudablemente, la urbanización es un fenómeno clave de este siglo, y es en las ciudades donde se están produciendo las grandes transformaciones demográficas, económicas y sociales: especialmente en las urbes de países en desarrollo. Esto está generando un nuevo paradigma que destaca los beneficios de la urbanización: incrementos en la productividad, mayor flexibilidad y fluidez de los mercados de trabajo, así como más y mejor acceso a los mercados, entre muchos otros. A diferencia de los años ochenta, ahora la pregunta no es cómo frenar la urbanización, sino cómo aprovechar las oportunidades que ofrece, y minimizar los riesgos inherentes a la conformación de grandes ciudades (por ejemplo: costos de congestión, inseguridad, segregación, contaminación, problemas de accesibilidad, por mencionar algunos).

Si esto es correcto a escala global, es aún más tangible a escala de nuestro país. Lamentablemente, México (y muchos países en desarrollo) siguen sin contar con una agencia gubernamental eficaz dedicada a la planeación de las ciudades, donde se está jugando, sin exagerar, el futuro de la nación. 